not describe experiments (of which I have made plenty) in proof of its occurrence.

(8) I quite agree with Mr. Cunningham and Mr. Henslow, that it is my duty to describe the effect I believe fine mud to have upon the respiratory apparatus, and I am preparing such a description as quickly as I can. I hope also to be able before long to answer Mr. Cunningham's last and very pertinent question, whether crabs of given length, from the clear water outside Plymouth Sound, are broader or narrower than crabs of the same length from muddy waters within the Sound.

(9) I altogether fail to understand Mr. Henslow's letter, and I fear that my imperfect exposition has led him to misunder. stand me as completely as he has misunderstood one of the clearest passages in the "Origin of Species." Mr. Henslow suggests that a variation, fit to afford material for natural selection, must be a ntw character, differing in some mysterious and undefined way from those individual differences which he refuses to call variations; and he further attributes the same view to Mr. Darwin. If Mr. Henslow will read once more the section of the fourth chapter of the "Origin of Species " headed "IIlustrations of the Action of Natural Selection, \&c.," he will see that Mr. Darwin does not express this opinion. The important thing to determine is not what any man, however eminent, has said about the importance of differences between individual animals, but what that importance can be shown to be. The crabs at Plymouth have not, during the past five years, exhibited any changes in the magnitude of their frontal breadth which Mr. Henslow would rank as a variation, but they have exhibited individual differences. During these five years the mean frontal breadth ratio has changed nearly 2 per cent., so that the change now going on would produce, if it were to continue at the same rate for fifty years, a change big enough to constitute a difference which most men would rank as specific. I have endeavoured to show that this change has been accompanied by a destruction which has acted selectively upon individual differences. $\mathrm{Mr}$. Henslow has not seriously discussed this attempt of mine, but ridicules the idea that so small a change can be of importance in relation to evolution. If the mean stature of Englishmen were to diminish by an inch in a few years, I presume Mr. Henslow would regard such change as rapid and important ; but the percentage change would be less than that which Mr. Thompson and I have demonstrated during the past five years in crabs. W. F. R. WELDON.

\section{Mirage on City Pavements.}

DURING my summer visits to San Francisco, I have been so frequently struck with the beautiful miniature mirages that can be seen on the flagstone sidewalks whenever the sun shines, that I determined to secure, if possible, a photograph of the phenomenon on a scale suitable for reproduction. One or two

walk is flooded with a perfectly smooth sheet of water, in which the reflections of pedestrians can be seen as distinctly as in a mirror.

In order to observe the phenomenon it is necessary that a considerable stretch of level pavement be foreshortened into a very narrow strip. This is the condition in the photograph: the camera stood just below the brow of the hill, and the distance in the photograph from the $\mathrm{X}$ to where the children and the toy cart are standing, is an entire block ( 135 yards). The position of the camera and section of the hill-top are shown in the diagram. The apparent reflections, due to the

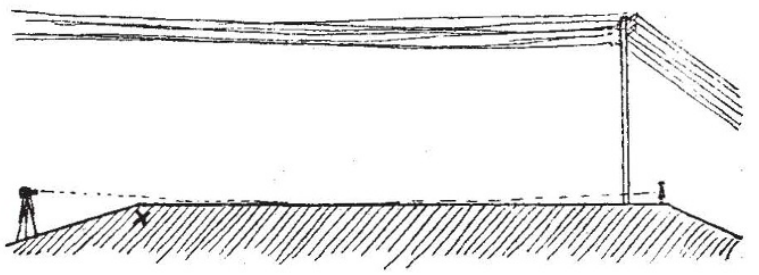

bending upward of the rays by the thin layer of heated air, come out very clearly in the picture, but the camera fails to give a correct reproduction of the extreme brilliancy of the reflecting layer of air.

On taking a few steps up the hill, decreasing the foreshortening, the glaze vanishes, and we see only the dull grey of the flagstones. Extremely hot sunshine is not necessary. I have observed the phenomenon early in the morning after a cold night, befure the sun had reached the pavement, the slight warmth from the ground being sufficient. Under these conditions, however, the pavement must be more foreshortened than when in the full sunshine. The refracting layer is probably only a thin skin of warm air, which adheres as it were to the surface of the flagstones, for the mirage is unaffected by the strong winds which frequently sweep the top of the hill.

Probably these mirages can be seen on any level pavement where the eye can be brought into the proper position.

Physical Department of the University, R. W. Wood.

Madison, Wisconsin, September 20.

\title{
Transference of Heat in Cooled Metal.
}

My attention has just been called to two communications to your journal, entitled "Transference of Heat in Cooled Metal." The first, by M. Henry Bourget, appears in the issue of June 3o, and the second, by Mr. Albert T. Bartlett, in the issue of September I.

About the year I880 I had occasion to heat one end of an iron bar to a bright red heat whilst holding the cooler end in my hand. Upon plunging the heated end into a bucket of water the cooler end became suddenly so hot that I was obliged to release my hold on it.

This phenomenon interested me very much, as I could find no explanation for the apparent reflection of heat to the cooler end of the bar; and in 1888 , whilst working in the physical laboratory at Johns Hopkins University, I further investigated the matter.

To one end of an iron or steel bar was soldered a thermoelectric couple, the circuit of which was closed through a very

previous attempts in past years having been partial failures owing to the smallness of the image, I secured, through the kindness of a friend, the use of a very fine tele-objective capable of giving an image six or. eight times as large as an ordinary objective of $\mathrm{x} 2$ inches focus. The streets over some of the hills are so laid out that it is possible, on nearing the brow, to bring the eye on the level of the side-walk, and look along a perfectly level stretch of one hundred yards or more. Standing in this position it is almost impossible to resist the conviction that the sensitive, high resistance, Rowland, reflecting, galvanometer.
The bar was passed through two pasteboard screens, and was supported in a horizontal position, the screens serving to intercept any heat which might be conveyed by radiation or convection through the air from one end of the bar to the other. Under the end of the bar, remote from that to which the thermo-electric couple was soldered, was placed a compound bunsen burner, by which the end of the bar was raised to a dul red heat. The spot of light on the galvanometric scale NO. I 5 I 2 VOL. $5^{8}$ ] 